\title{
Endovascular exclusion of the entire aortic arch with branched stent-grafts after surgery for acute type $A$ aortic dissection
}

Augusto D'Onofrio, MD, PhD, ${ }^{a}$ Giorgia Cibin, MD, ${ }^{\mathrm{a}}$ Michele Antonello, MD, ${ }^{\mathrm{b}}$ Piero Battocchio, MD, ${ }^{\mathrm{b}}$ Michele Piazza, MD, ${ }^{\mathrm{b}}$ Raphael Caraffa, MD, ${ }^{\mathrm{a}}$ Alberto Dall'Antonia, MD, ${ }^{\mathrm{b}}$ Franco Grego, MD, ${ }^{\mathrm{b}}$ and Gino Gerosa, MD

\section{ABSTRACT}

Background: The treatment of residual pathology of the aortic arch after surgical repair for type $A$ acute dissection (AAD) represents a therapeutic challenge. Recently, new branched endovascular devices have expanded the possibility of aortic arch stent-grafting (ASG) with proximal landing in zone o. The aim of this retrospective, single-center study was to evaluate outcomes of patients with a history of surgical repair for AAD undergoing ASG with branched devices.

Methods: We analyzed patients undergoing ASG after treatment for type AAD with 2 different branched devices: Nexus (dual-module, single branch, off-the-shelf) and RelayBranch (single-module, dual branch, custom-made). Before ASG, surgical bypass of supra-aortic vessels was performed according to patient's anatomy and to the selected device. All patients underwent clinical and computed tomography scan evaluation before hospital discharge, at 6 months, and on a yearly basis thereafter.

Results: From March 2017 to April 2019, 4 consecutive patients underwent ASG after surgery for AAD at our institution. Mean time from surgery for AAD to ASG was 20 months. Mean age at the time of ASG was 72 years. Nexus and Relay were implanted in 2 patients each. All patients survived and were successfully discharged. Mean intensive care unit stay and hospital stay were 3 and 19 days, respectively. We did not observe any major adverse events. At a mean follow-up of 28 months, all patients are alive and computed tomography scans showed good anatomic results with no endoleaks.

Conclusions: This preliminary experience shows that ASG after surgery for AAD is feasible and provides encouraging clinical and anatomic early results. (JTCVS Techniques 2020;3:1-8)

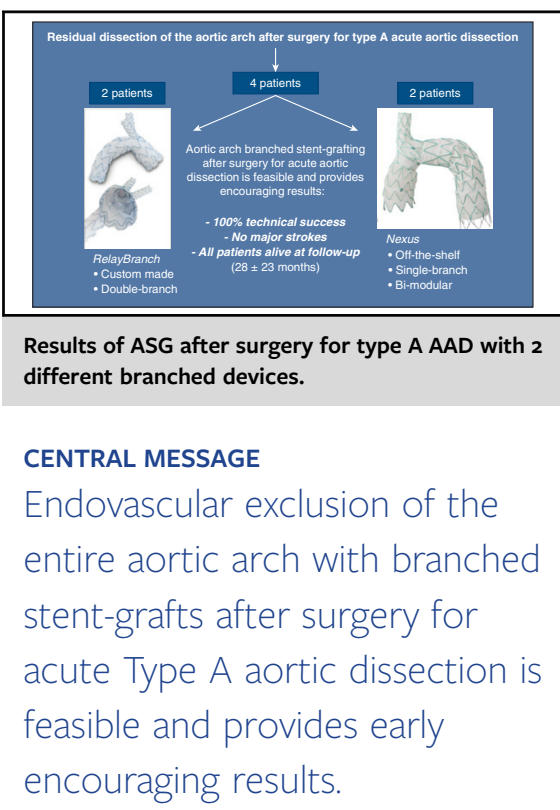

\section{PERSPECTIVE}

In this era or (re)-evolution of our specialty toward less invasiveness, endovascular stentgrafting of the aortic arch with branched devices in high-risk patients, as those with a history of surgery for type A aortic dissection, should be considered as another tool in the armamentarium of cardiac surgeons. In the future, it might lead to a proximalization of the correction of type A aortic dissection.

See Commentaries on pages 9 and 11.
From the Divisions of ${ }^{\mathrm{a}}$ Cardiac Surgery, and ${ }^{\mathrm{b}}$ Vascular Surgery, University of Padova, Padova, Italy.

Presented at the 99th Annual Meeting of The American Association for Thoracic Surgery, Toronto, Ontario, Canada, May 4-7, 2019.

Received for publication April 13, 2020; revisions received April 13, 2020; accepted for publication April 16, 2020; available ahead of print April 28, 2020.
Address for reprints: Augusto D'Onofrio, $\mathrm{MD}, \mathrm{PhD}$, Division of Cardiac Surgery, Department of Cardiac, Thoracic and Vascular Sciences, University of Padova, Viale Giustiniani, 2, 35128, Padova, Italy (E-mail: adonofrio@ hotmail.it). 2666-2507

Copyright $(2020$ The Authors. Published by Elsevier Inc. on behalf of The American Association for Thoracic Surgery. This is an open access article under the CC BY-NCND license (http://creativecommons.org/licenses/by-nc-nd/4.0/).

https://doi.org/10.1016/j.xjtc.2020.04.009 


\section{Abbreviations and Acronyms}
$\mathrm{AAD}=$ type $\mathrm{A}$ acute aortic dissection
ASG = aortic arch stent-grafting
$\mathrm{BCT}=$ brachiocephalic trunk
$\mathrm{CT}=$ computed tomography
LCCA $=$ left common carotid artery
LSA = left subclavian artery
$\mathrm{RCCA}=$ right common carotid artery

Video clip is available online.

To view the AATS Annual Meeting Webcast, see the URL next to the webcast thumbnail.

Residual dissection of the aortic arch and proximal descending aorta after replacement of the ascending aorta for type A acute aortic dissection (AAD) often requires reoperation during follow-up due to a progressive growth that may occur in up to $75 \%$ of patients. ${ }^{1}$ The gold standard therapy for these patients is redo open surgical repair with aortic arch replacement and reimplantation of supra-aortic vessels performed under cardiopulmonary bypass with deep or moderate hypothermic circulatory arrest and selective antegrade cerebral perfusion. ${ }^{2}$ This operation is technically demanding and is associated with significant morbidity and mortality, especially in high-risk patients. ${ }^{3}$ Recently, endovascular total aortic arch exclusion with proximal landing in Ishimura zone 0 and distal landing in zone 3 using branched stent-grafts has been proposed as a therapeutic alternative to open surgery in inoperable or high-risk patients. ${ }^{4}$ This procedure allows aortic arch repair with a microinvasive approach; in fact, it is performed on the beating heart and with no cardiopulmonary bypass, thus reducing the impact of surgery in this delicate cohort of patients. ${ }^{5,6}$ There is a lack of data regarding results of aortic arch stent-grafting (ASG) in the case of residual progressive dissection after surgery for $\mathrm{AAD}$. Therefore, the aim of this retrospective, singlecenter study was to evaluate outcomes of patients undergoing ASG after surgery for AAD.

\section{METHODS}

We analyzed the data of all consecutive patients who underwent ASG with branched devices for residual progressive dissection of the aortic arch after surgery for AAD at our institution. All patients were discussed during local aortic team meetings (cardiac surgeon, vascular surgeon, and anesthesiologist) and were deemed inoperable or at prohibitive risk for open surgery. Indications for ASG were (1) maximal aortic arch diameter $\geq 55 \mathrm{~mm}$; (2) rapid increase of aortic diameter $(\geq 1 \mathrm{~cm}$ in 1 year); and (3) pseudoaneurysm with compression of surrounding structures. All eligible patients underwent careful evaluation based on angio-computed tomography (CT) scan to assess anatomic feasibility. In particular, the most important anatomical aspects to evaluate were proximal and distal landing zone (length and diameter), length of the inner and of the outer curvature of the ascending aorta, shape of the aortic arch, size and tortuosity of supra-aortic vessels as well as their take-off angle from the arch, possibility to perform an effective revascularization of supra-aortic vessels, and shape and anatomy of the dissection membrane. The dissection of supra-aortic vessels was not an absolute contraindication for this procedure, as long as an optimal landing zone or the possibility to prolong stenting distally was present. The diameter of the ascending surgical graft is generally not a limiting factor in this specific population because the maximum ascending aorta diameter for the Nexus and RelayBranch is $40 \mathrm{~mm}$ and $43 \mathrm{~mm}$, respectively. These values are significantly larger than commonly implanted vascular grafts. In this study, the proximal landing in Ishimura zone 0 was always into the ascending vascular prosthesis of the first operation and a minimal length of $25 \mathrm{~mm}$ was considered to obtain good proximal sealing. Informed consent for the procedure and for data collection was obtained for all patients. Since during the study period one device was still not CE-marked, compassionate use authorization from Ministry of Health and from local Ethics Committee was required and obtained in 1 case.

\section{Study Devices and Procedure}

In this study, we used the following 2 different branched stent-grafts:

- Nexus (Endospan, Herzlia, Israel) is made of 2 components: a main module for the aortic arch and the descending aorta with a side-branch for one supra-aortic vessel and a curved module for the ascending aorta that connects to the main module through a side-facing, self-protecting sleeve and lands into the sinotubular junction (Figure 1). This is an "off-the-shelf" device that comes into different sizes to fit the great majority of aortic anatomies. The technical steps of Nexus implantation have been already described. ${ }^{7}$ To summarize in brief, through a femoral access and a through-and-through guidewire (whose configuration depends on the selected vessel that will accommodate the branch), the distal portion of the first module lands in one of the supra-aortic vessels and then stent opening continues into the aortic arch and the descending aorta. The second module is then deployed into the ascending aorta during rapid pacing. The landing zone for the second module is identified by a tantalum radio-opaque ring.

- RelayBranch Thoracic Stent-Graft System (Terumo Aortic, Glasgow, United Kingdom) is a custom-made device featuring a window in the superior portion of the stent graft that accommodates 2 inner tunnels where branches for the brachiocephalic trunk (BCT) and for the left common carotid artery are positioned (Figure 2). Stent grafts were manufactured according to preoperative angio-CT scan measurements. Turnaround time from order to delivery was around 4 weeks. Radiopaque markers help to achieve correct positioning of the device and of its window as well as appropriate positioning of the branches in the 2 tunnels. Specific lock-stent systems in the tunnels prevent disconnection of the branches from the tunnels. Details on the RelayBranch implantation technique have been already described. ${ }^{8}$ To summarize in brief, through a femoral access, a stiff guidewire is positioned in the left ventricle and the main stent-graft is advanced and then deployed in the aorta during rapid pacing. Then, through a bilateral cervical access, the 2 branches are retrogradely positioned into the tunnels in a sequential fashion.

For the deployment of both devices, a guidewire is usually placed in the left ventricle as for a standard transfemoral aortic valve replacement. Alternatively, a "loop" can be made to avoid crossing the aortic valve or of if retrogade crossing of the aortic valve results are technically difficult. In our series, all patients had an aortic bioprosthesis that allowed an easy positioning of the guidewire in the left ventricle. In case of a mechanical aortic valve prosthesis, the use of these devices is not recommended, since both 


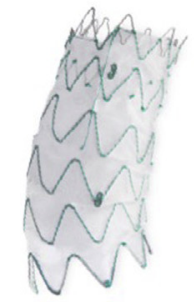

A

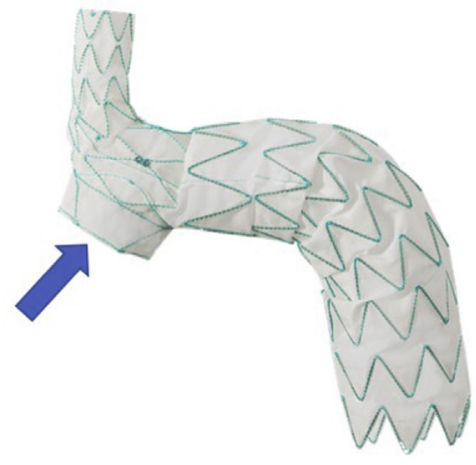

B

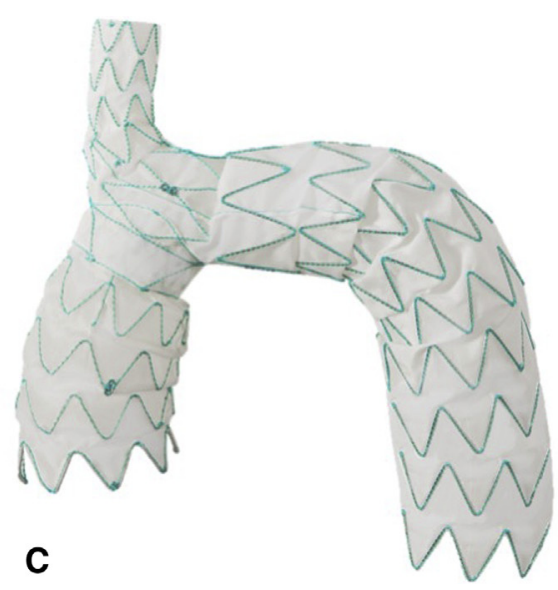

C

FIGURE 1. Nexus stent graft system. This device has 2 modules. The ascending module (A) is curved and connects to the main module (B) through a side-facing self-projecting sleeve (arrow). The assembled device is shown in panel C.

the guidewire and the nosecone of the delivery system would interfere and potentially damage metallic valve leaflets.

Device selection was made according to the anatomy and to the clinical profile of each single patient. Single-branch off-the-shelf Nexus was chosen in 1 patient who had just 1 supra-aortic vessel eligible for stent implantation (left subclavian artery) and in 1 patient with a rapidly growing anastomotic pseudoaneurysm. Double-branch custom-made RelayBranch was chosen in 2 patients with good landing zones in the innominate artery

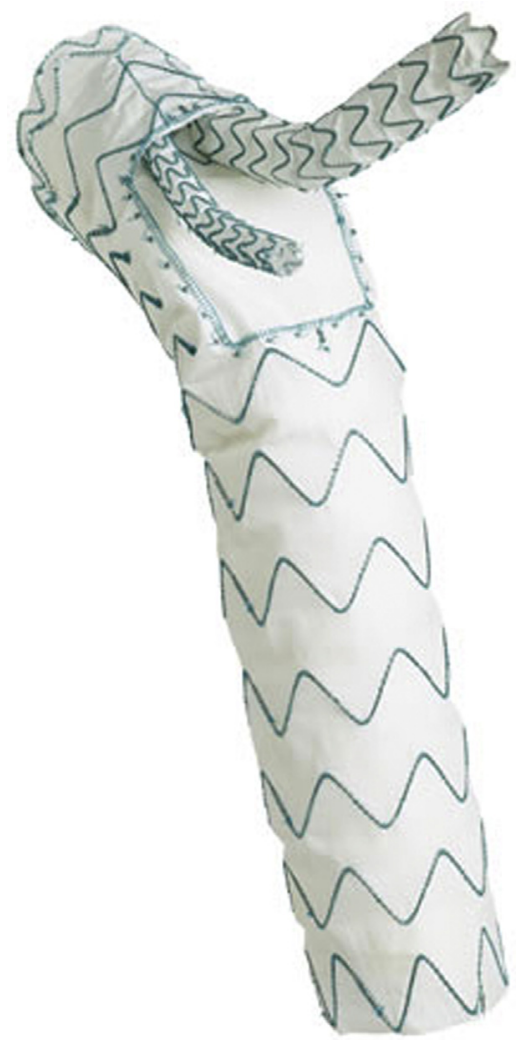

FIGURE 2. RelayBranch system. This device has a main body with a window that hosts 2 inner tunnels for retrograde positioning of the supra-aortic branches. and in the left carotid artery and with stable conditions that allowed enough time for device manufacturing.

Before ASG, surgical bypass of the supra-aortic vessels was performed according to the planned endovascular strategy (single-branch, double-branch, supra-aortic target vessel). This can be performed during the same operation or in a separate procedure a few days before. After ASG, during the same operation, the remaining patent origins of the bypassed supra-aortic vessels were closed with endovascular plugs to avoid type 2 endoleak. All ASG procedures were performed, with the patient under general anesthesia, by a cardiac surgeon and a vascular surgeon who equally shared all the steps of the operation. Intraoperative brain perfusion was monitored by using near-infrared spectroscopy. Technical success was defined as correct delivery and deployment at the intended location of all the endografts, with patency of the grafts and supra-aortic target vessels and without any type I or type III angiographically detected endoleak. ${ }^{9}$ All patients underwent clinical and CT scan evaluation before hospital discharge, at 6 months, and on a yearly basis thereafter.

\section{Statistical Analysis}

Continuous data are presented as mean \pm standard deviation. Data were prospectively collected in a specific database and retrospectively analyzed.

\section{RESULTS}

From March 2017 to April 2019, 4 consecutive patients (1 female) underwent ASG with branched devices after surgical repair for AAD at our institution. Preoperative clinical characteristics are shown in Table 1, and the preoperative angio-CT scan of all patients is shown in Video 1. Mean age was $72 \pm 3$ years. All patients underwent modified Bentall operation ("Button technique") with a biologic composite graft for AAD. Mean time from surgery to ASG was $20 \pm 21$ months (range 2.5-50 months). Nexus and RelayBranch were implanted in 2 patients each. The supra-aortic bypass strategy is shown in Figure 3. The 2 patients receiving the RelayBranch underwent a left common carotid artery (LCCA)-left subclavian artery (LSA) bypass before ASG during the same procedure (Figure 3, A). One patient receiving Nexus underwent LSA-right common carotid artery bypass with 
TABLE 1. Preoperative clinical characteristics

\begin{tabular}{|c|c|c|c|c|c|c|c|c|c|}
\hline Patient & Sex & $\begin{array}{c}\text { Age, } \\
\mathbf{y}\end{array}$ & Medical history & $\begin{array}{c}\text { STS- } \\
\text { PROM }\end{array}$ & $\begin{array}{c}\text { EuroScore } \\
2 \\
\end{array}$ & $\begin{array}{c}\text { Previous operation } \\
\text { (all TAAAD) }\end{array}$ & $\begin{array}{c}\text { Time from } \\
\text { previous } \\
\text { operation to } \\
\text { endovascular } \\
\text { stent graft, } d \\
\end{array}$ & $\begin{array}{c}\text { Indications for } \\
\text { endovascular } \\
\text { stent graft }\end{array}$ & $\begin{array}{c}\text { Max } \\
\text { aortic } \\
\text { diameter }\end{array}$ \\
\hline 1 & Male & 72 & $\begin{array}{l}\text { Arterial } \\
\text { hypertension; } \\
\text { ex-smoker }\end{array}$ & 1.93 & 4.01 & $\begin{array}{l}\text { Bentall procedure } \\
\text { (Magna Ease } \\
25 \mathrm{~mm}+ \\
\text { Vascutek } 30 \mathrm{~mm} \text { ) }\end{array}$ & 1483 & $\begin{array}{l}\text { Residual dissection } \\
\text { of the aortic arch } \\
\text { with progressive } \\
\text { dilatation during } \\
\text { follow-up }\end{array}$ & $61 \mathrm{~mm}$ \\
\hline 2 & Male & 67 & $\begin{array}{l}\text { Arterial } \\
\text { hypertension; } \\
\text { smoker }\end{array}$ & 1.39 & 3.49 & $\begin{array}{l}\text { Modified Bentall } \\
\text { procedure - } \\
\text { Button technique } \\
\text { (Magna Ease } 25+ \\
\text { Vascutek } 32 \mathrm{~mm} \text { ) }\end{array}$ & 311 & $\begin{array}{l}\text { Residual dissection } \\
\text { of the aortic arch } \\
\text { with progressive } \\
\text { dilatation during } \\
\text { follow-up }\end{array}$ & $58 \mathrm{~mm}$ \\
\hline 3 & Female & 75 & $\begin{array}{l}\text { Arterial } \\
\text { hypertension; } \\
\text { PVD; } \\
\text { CKD; } \\
\text { previous } \\
\text { stroke; } \\
\text { AF }\end{array}$ & 4.58 & 11.0 & $\begin{array}{l}\text { Bentall procedure } \\
\quad \text { (Freestyle aortic } \\
\text { root } 23 \mathrm{~mm}+ \\
\text { intervascular } 30 \mathrm{~mm} \text { ) }\end{array}$ & 525 & $\begin{array}{l}\text { Residual dissection } \\
\text { of the aortic arch } \\
\text { with progressive } \\
\text { dilatation during } \\
\text { follow-up }\end{array}$ & $57 \mathrm{~mm}$ \\
\hline 4 & Male & 74 & $\begin{array}{l}\text { Arterial } \\
\quad \text { hypertension; } \\
\text { dyslipidemia; } \\
\text { type II DM; } \\
\text { ex-smoker; } \\
\text { PVD; } \\
\text { COPD; } \\
\text { CKD }\end{array}$ & 3.65 & 10.72 & $\begin{array}{l}\text { Bentall procedure } \\
\text { (Magna Ease } \\
25 \mathrm{~mm}+ \\
\text { jOTEC } 30 \mathrm{~mm} \text { ) }\end{array}$ & 75 & $\begin{array}{l}\text { Rapidly growing } \\
\text { pseudoaneurysm } \\
\text { of the aortic arch } \\
\text { originating from the } \\
\text { distal anastomosis } \\
\text { with compression on } \\
\text { the pulmonary artery }\end{array}$ & N/A \\
\hline
\end{tabular}

STS-PROM, Society of Thoracic Surgeons-Predicted Risk of Mortality; TAAAD, type A acute aortic dissection; $P V D$, peripheral vascular disease; $C K D$, chronic kidney disease; $A F$, atrial fibrillation; $D M$, diabetes mellitus; $C O P D$, chronic obstructive pulmonary disease; $N / A$, not available.

reimplantation of the LCCA because the supra-aortic branch was positioned into the LSA (Figure 3, B). The other patient receiving Nexus underwent right common carotid artery-LCCA-LSA bypass because the supra-aortic branch was positioned into the BCT (Figure 3,B). Procedural details are highlighted in Table 2, and the implantation of the 2 devices is shown in Video 2. Technical success was achieved in all cases $(100 \%)$. We did not experience any issue related to the presence of dissected vessels during navigation of the aorta with wires, catheters, and delivery systems. All patients survived the procedure and were successfully discharged. Mean intensive care unit and hospital stay were $3 \pm 2$ and $19 \pm 2$ days, respectively. We observed one minor stroke (dysarthria, positive CT scan) with full recovery within 4 days in 1 patient; we did not observe any other major postoperative complications. Predischarge CT scan showed good positioning and absence of endoleak in all patients. At a mean follow-up of $28 \pm 23$ (range 11-60) months, all patients are alive and in good clinical condition (Figure 4). Two patients underwent distal thoracic endovascular aortic repair for persistent patency of the false lumen 16 and 22 months after ASG.

\section{DISCUSSION}

This initial experience demonstrated that endovascular stent-grafting of the aortic arch in highly selected patients with residual dissection after surgery or type A acute is feasible, safe, and effective. The most important issues that this study, focused on this particularly challenging group of patients, brings to light are mainly related to patient selection, device selection, technical feasibility, endoleaks, stability of the graft, and early clinical outcomes of this procedure. Accurate patient selection in terms of clinical and anatomic characteristics, as well as correct device selection, are mandatory to predict good procedural outcomes. Although it should always be considered that conventional surgery is still the first choice, the complexity of these patients makes it possible that some of them, due to technical and clinical characteristics, are too high risk for surgery and therefore the microinvasive endovascular option could be considered. There are several endovascular 


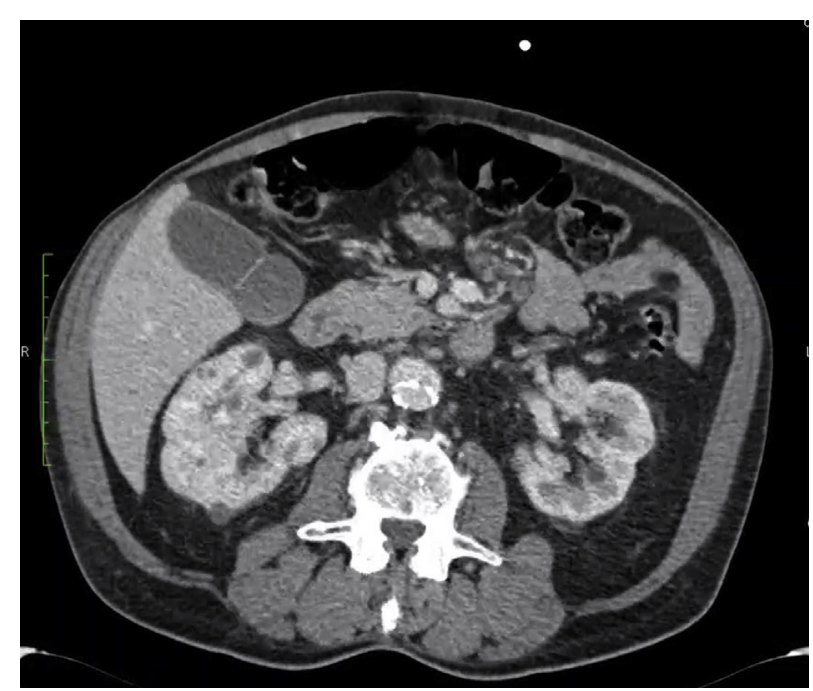

VIDEO 1. Preoperative angio CT-scan of all patients. The first 3 patients show residual dissection and dilatation of the aortic arch; the fourth patient had a rapidly growing pseudoaneurysm of the aortic arch originating from the distal anastomosis with compression on the pulmonary artery. Video available at: https://www.jtcvs.org/article/S2666-2507(20)30200-5/ fulltext.

options for the aortic arch: branch devices like in our series, fenestrated grafts, ${ }^{10,11}$ in situ graft fenestration, ${ }^{12,13}$ and chimney techniques. ${ }^{14}$ Careful preoperative evaluation with angio-CT scan allows one to evaluate feasibility and to choose the most appropriate device. In patients with residual dissection of the aortic arch, the presence of a surgical vascular prosthesis in the ascending aorta always allows a stable and safe proximal landing in zone 0 , provided that at least $2.5 \mathrm{~cm}$ is available above the coronary ostia and that the vascular graft is not kinked. For this reason, particular attention should be given during surgery for type A acute aortic dissection (whether it is a Bentall or an isolated ascending replacement) to position an ascending vascular graft of at least $3 \mathrm{~cm}$ in the shorter curvature and $5 \mathrm{~cm}$ in the longer curvature and that does not kink. Proximal landing in a surgical graft minimizes also the risk of type IA endoleak. Furthermore, length, diameter, and involvement in the residual dissection of supra-aortic vessels should be evaluated. Device selection is crucial and the possibility to have different devices with different features enables one to extend the number of treatable patients and guarantees the choice of the most appropriate device for every single patient. Nexus has one branch, is "off-the-shelf," and does not require retrograde insertion of supra-aortic branches since it requires an axillary-femoral "throughand-through" guidewire for implantation. Therefore, it is particularly indicated in patients with one suitable supraaortic target vessel (usually BCT or LSA; LCCA is generally too narrow), urgent cases, patients with diseased supra-aortic vessels that don't allow placement of big sheaths, or a retrograde branch insertion. However, Nexus requires double surgical bypass for supra-aortic revascularization. RelayBranch has 2 branches, is custom-made, and requires a single bypass for supra-aortic revascularization (usually LCCA-LSA); nevertheless, it requires surgical cut-down of the neck and retrograde insertion of the branches and therefore it is indicated in elective cases in which anatomy allows safe double-branch retrograde delivery. In our study, we used the 2 devices in 2 patients each. In particular, Nexus was used in 1 patient with a rapidly growing pseudoaneurysm of the arch and in another case in whom the only suitable target vessel was the LSA, whereas RelayBranch was adopted in 2 elective cases with suitable BCT and LCCA. As far as technical feasibility is concerned, there are many anatomical aspects that should be evaluated for a potential ASG candidate, especially in
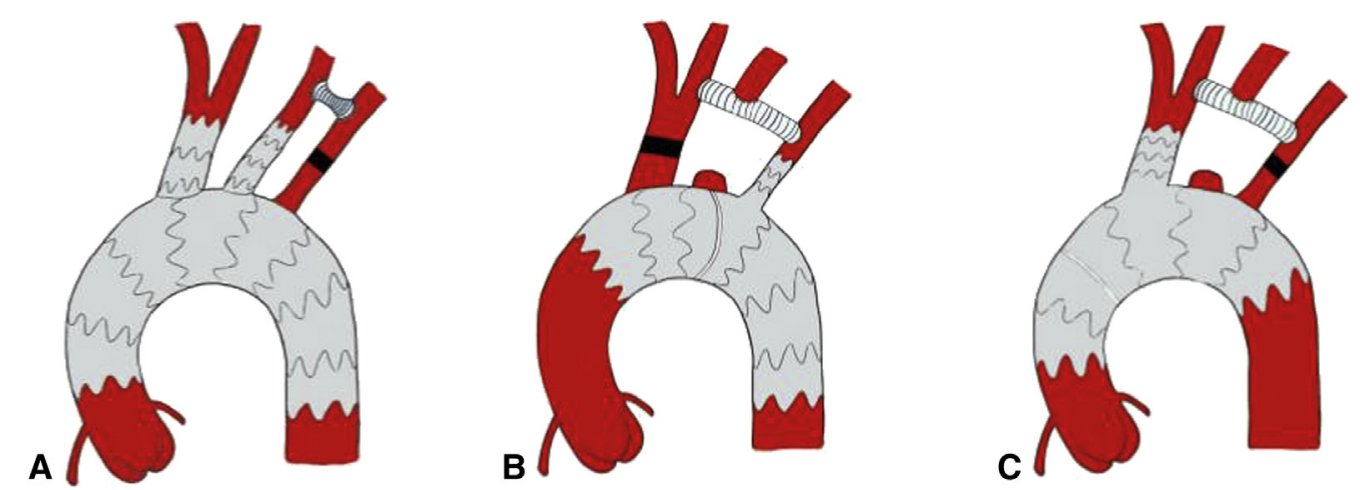

FIGURE 3. A, Aortic arch stent-grating with double-branch device (RelayBranch). The 2-supra-aortic branches are positioned in the innominate artery and in the left common carotid artery. The left subclavian artery is reperfused through a carotid-subclavian bypass. B, Aortic arch stent-grafting with single-branch device (Nexus). In this case, the side-branch is positioned in the left subclavian artery and supra-aortic vessels are reperfused through a subclavian-left carotid-right carotid bypass; a vascular plug is positioned in the innominate artery. $\mathrm{C}$, In this case, the side branch is positioned in the innominate artery and supra-aortic vessels are reperfused through a right carotid-left carotid-left subclavian bypass; a vascular plug is positioned in the left subclavian artery. 
TABLE 2. Procedural details

\begin{tabular}{|c|c|c|c|c|c|c|c|c|c|c|c|c|c|c|}
\hline Patient & Device & $\begin{array}{c}\text { Main graft } \\
\text { vascular } \\
\text { access }\end{array}$ & $\begin{array}{c}\text { Branch graft } \\
\text { vascular access }\end{array}$ & $\begin{array}{l}\text { Embolization/ } \\
\text { ligation }\end{array}$ & $\begin{array}{l}\text { Fluoroscopy } \\
\text { time, min }\end{array}$ & $\begin{array}{c}\text { Contrast } \\
\text { volume, } \\
\text { mL }\end{array}$ & $\begin{array}{l}\text { Rapid } \\
\text { pacing }\end{array}$ & $\begin{array}{l}\text { Debranching } \\
\text { timing }\end{array}$ & $\begin{array}{c}\text { Procedural } \\
\text { success }\end{array}$ & $\begin{array}{c}\text { ICU } \\
\text { stay, } \\
\text { d }\end{array}$ & $\begin{array}{c}\text { Hospital } \\
\text { stay, d }\end{array}$ & Endoleak & $\begin{array}{c}\begin{array}{c}\text { Postop } \\
\text { complications }\end{array}\end{array}$ & Follow-up \\
\hline 1 & Relay & $\begin{array}{l}\text { CFA, } \\
\text { percutaneous }\end{array}$ & $\begin{array}{r}\text { Both CCA, } \\
\text { surgical }\end{array}$ & $\begin{array}{l}\text { LSA vascular } \\
\text { plug }\end{array}$ & 49 & 190 & Yes & $\begin{array}{l}\text { During } \\
\text { the index } \\
\text { procedure }\end{array}$ & Yes & 6 & 20 & No & $\begin{array}{l}\text { Minor stroke } \\
\quad \text { (dysarthria) } \\
\text { with full } \\
\text { recovery }\end{array}$ & $12 \mathrm{mo}$, alive \\
\hline 2 & Relay & $\begin{array}{l}\text { CFA, } \\
\text { percutaneous }\end{array}$ & $\begin{array}{r}\text { Both CCA, } \\
\text { surgical }\end{array}$ & $\begin{array}{l}\text { LSA vascular } \\
\text { plug }\end{array}$ & 43 & 169 & Yes & $\begin{array}{l}\text { During } \\
\text { the index } \\
\text { procedure }\end{array}$ & Yes & 1 & 17 & No & No & $\begin{array}{l}27 \text { mo, alive } \\
\text { CT scan: } \\
\text { thoracic } \\
\text { aneurysm; } \\
\text { underwent } \\
\text { subsequent } \\
\text { TEVAR } \\
22 \text { mo } \\
\text { after the } \\
\text { procedure }\end{array}$ \\
\hline 3 & Nexus & $\begin{array}{l}\text { CFA, } \\
\text { percutaneous }\end{array}$ & $\begin{array}{l}\text { LHA-LFA, } \\
\text { percutaneous }\end{array}$ & $\begin{array}{l}\text { BCT vascular } \\
\text { plug }\end{array}$ & 47 & 183 & Yes & $\begin{array}{l}4 \mathrm{~d} \text { before } \\
\text { the index } \\
\text { procedure }\end{array}$ & Yes & 2 & 21 & No & $\begin{array}{l}\mathrm{AF} \\
\quad \text { paroxysmal }\end{array}$ & $\begin{array}{l}60 \text { mo, alive. } \\
\text { CT scan: residual } \\
\text { type B } \\
\text { dissection; } \\
\text { underwent } \\
\text { subsequent } \\
\text { TEVAR } \\
16 \text { mo } \\
\text { after the } \\
\text { procedure }\end{array}$ \\
\hline 4 & Nexus & $\begin{array}{l}\text { CFA, } \\
\text { percutaneous }\end{array}$ & $\begin{array}{l}\text { RHA-LFA, } \\
\text { percutaneous }\end{array}$ & $\begin{array}{l}\text { LSA vascular } \\
\text { plug }\end{array}$ & 42 & 160 & Yes & $\begin{array}{l}6 \mathrm{~d} \text { before } \\
\text { the index } \\
\text { procedure }\end{array}$ & Yes & 3 & 17 & No & No & $11 \mathrm{mo}$, alive \\
\hline
\end{tabular}

$I C U$, Intensive care unit; $C F A$, common femoral artery; $C C A$, common carotid artery; $L S A$, left subclavian artery; $C T$, computed tomography; $T E V A R$, thoracic endovascular aortic repair; $L H A$, left humeral artery; $L F A$, left femoral artery; $B C T$, brachiocephalic trunk; $A F$, atrial fibrillation; $R H A$, right humeral artery.

patients with a history of surgery for type A acute dissection: proximal landing zone in a vascular graft (size and length of the graft in the inner and outer curvature, distance from the coronary ostia, kinking of the graft); distal landing zone and potential additional distal stent implantation; shape of the aortic arch (patients with gothic arch are not usually eligible); size, length, condition (dissected, calcified, etc); and take off angle of supra-aortic-vessels. Thus,

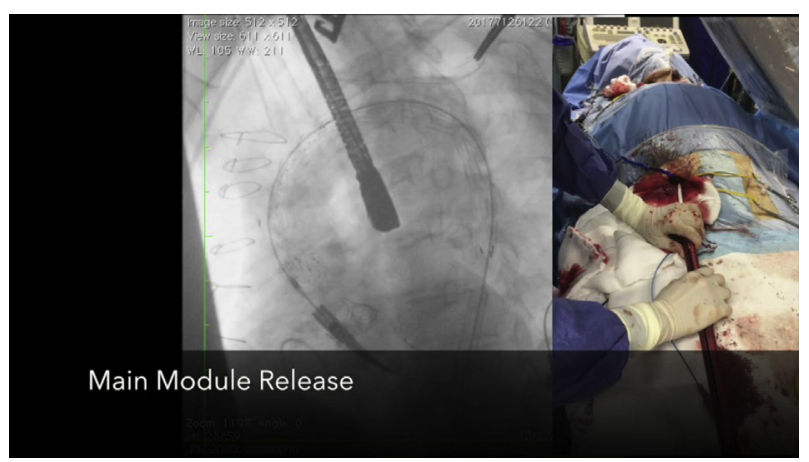

VIDEO 2. Pre-, intra-, and postoperative imaging of 2 cases of aortic arch stent-grafting, one for each study device. The first part shows the implantation of the double-branch custom made RelayBranch device. The second part shows the implantation of the single-branch off-the-shelf Nexus device. Video available at: https://www.jtcvs.org/article/S26662507(20)30200-5/fulltext. a thorough and careful preoperative evaluation is mandatory before scheduling a patient for ASG implantation.

Endoleaks are relatively frequent after stent-graft implantation, and the incidence reported in the literature ranges between $9 \%$ and $38 \% .{ }^{15}$ In our series, although with a limited number of patients, we haven't observed any endoleaks. This may be due to several reasons: proximal landing in a vascular prosthesis might reduce the incidence of type Ia endoleak; the absence of intercostal arteries and the positioning of endovascular plugs in patent supra-aortic vessels allows the elimination of type II endoleak; and proprietary locking systems enable a secure connection between the different parts of these devices, thus reducing the possibility of type III endoleak. The multiple anchoring points (ascending, descending, supra-aortic vessels) also significantly make device migration unlikely. Considering the high-risk characteristics of our patients, early results with no mortality nor major complications may allow us to be cautiously optimistic. In particular, endovascular treatment of the aortic arch has been associated with a non-negligible incidence of mortality and stroke. Ferrer and colleagues ${ }^{8}$ report $16.7 \%$ mortality and $12.5 \%$ major stroke rate in patients undergoing double-branch stent-graft implantation of the aortic arch. Nevertheless, mortality and major stroke rates for conventional surgery in reoperative aortic arch 


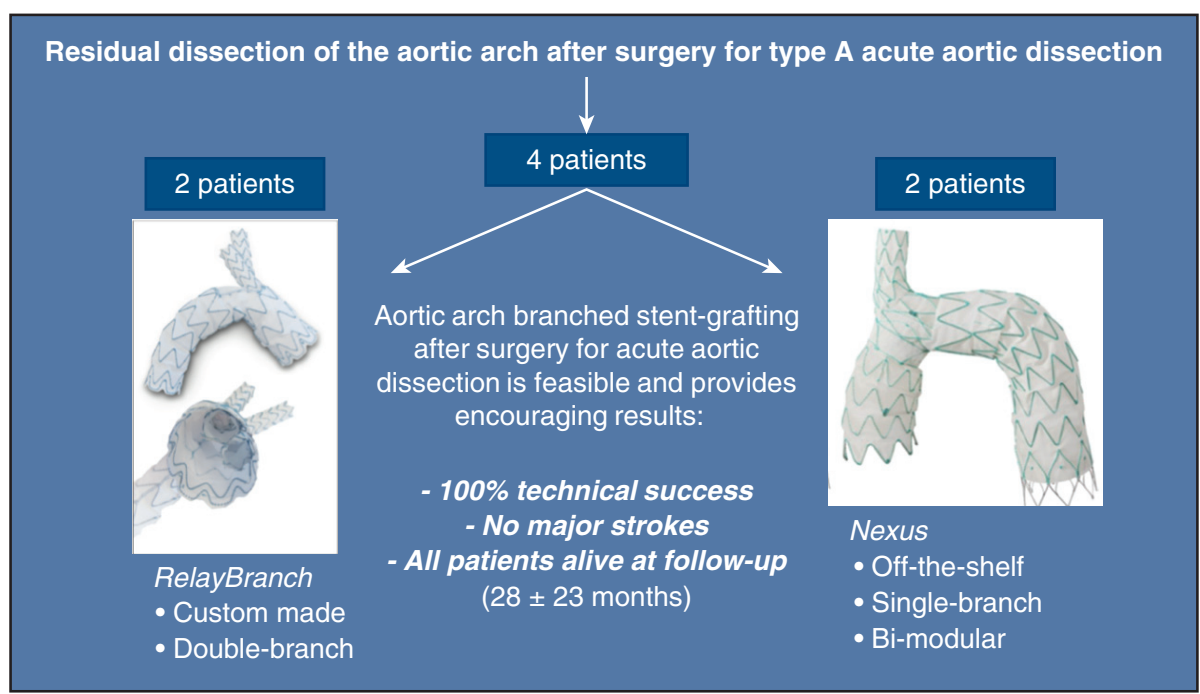

FIGURE 4. Results of aortic arch stent grafting after surgery for type A acute aortic dissection with 2 different branched devices: the custom-made, double-branch RelayBranch and the single-branch, bi-modular, off-the-shelf Nexus. Each device was implanted in 2 patients. We observed $100 \%$ technical success, no major complications, and all patients were alive and in good clinical conditions after a mean follow-up of 28 months.

replacement are $5 \%$ to $13 \%$ and $2 \%$ to $7 \%$, respectively. ${ }^{16,17}$ In these patients, cerebrospinal fluid drainage is never used, since the procedure involves the arch with limited extension into the distal descending aorta. If distal stent grafting is planned, cerebrospinal fluid drainage could be considered, as in every thoracic endovascular aortic repair procedure.

Another potential concern in patients undergoing ASG with branched stent-grafts is the fate of supra-aortic vessels bypass. Patency rate for these surgical bypasses has been reported to be more than $95 \%$ at 3 -year follow-up. ${ }^{18}$ In this regard, the advantage of double-branch devices is related to the single surgical bypass required for the LSA. As far as timing is concerned, we believe that ASG after surgery for type A acute aortic dissection can be performed whenever there is an indication for surgery on the arch, with no particular restrictions. Obviously, ASG early after conventional surgery for dissection could raise concerns related to the presence of recent anastomoses and weak aortic tissue and should be considered only in bail-out cases.

We are aware that the main limitation of this study is the small number of patients included in the analysis. However, this paper wants to be a proof of concept that endovascular exclusion of the entire aortic arch with branched stent-grafts after surgery for acute type A aortic dissection is feasible and provides early encouraging results. Longer follow-up and larger studies will be necessary to better assess early and late results of this technique. Should this endovascular approach demonstrate its effectiveness and reliability, there will be also implications for surgery for type A dissection leading to a proximalization of the correction and leaving to a second-stage endovascular procedure the completion of the correction only when needed. In this era or (re)-evolution of our specialty toward microinvasiveness, endovascular treatment of the aortic arch, also after surgery for AAD should be considered as another tool in the hands of cardiac surgeons for the treatment of this extremely delicate cohort of patients.

\section{Webcast}

You can watch a Webcast of this AATS meeting presentation by going to: https://aats.blob.core.windows.net/ media/19\%20AM/Tuesday_May7/206AC/206AC/S106\% 20- $\% 20$ Complex $\% 20$ operations $\% 20$ video $\% 20$ session/ S106_5_webcast_104843166.mp4.

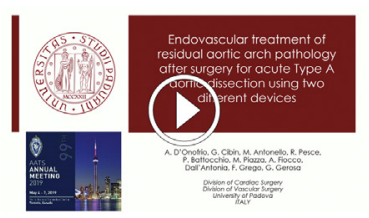

\section{Conflict of Interest Statement}

The authors reported no conflicts of interest.

The Journal policy requires editors and reviewers to disclose conflicts of interest and to decline handling or reviewing manuscripts for which they may have a conflict of interest. The editors and reviewers of this article have no conflicts of interest.

\section{References}

1. Rylski B, Hahn N, Beyersdorf F, Kondov S, Wolkewitz M, Blanke P, et al. Fate of the dissected aortic arch after ascending replacement in type A aortic dissection. Eur J Cardiothorac Surg. 2017;51:1127-34. 
2. Lou X, Chen EP. Optimal cerebral protection strategies in aortic surgery. Semin Thorac Cardiovasc Surg. 2019;31:146-52.

3. Martens A, Beckmann E, Kaufeld T, Umminger J, Fleissner F, Koigeldiyev N, et al. Total aortic arch repair: risk factor analysis and follow-up in 199 patients. Eur J Cardiothorac Surg. 2016;50:940-8.

4. Spear R, Haulon S, Ohki T, Tsilimparis N, Kanaoka Y, Milne CP, et al. Subsequent results for arch aneurysm repair with inner branched endografts. Eur J Vasc Endovasc Surg. 2016;51:380-5.

5. D'Onofrio A, Gerosa G. Technique versus technology and the (r)evolution of cardiac surgery: a professional journey from classical surgery to embracing intervention. Eur J Cardiothorac Surg. 2017;52:835-7.

6. D'Onofrio A, Gerosa G. Shifting a paradigm of cardiac surgery: from minimally invasive to micro-invasive. J Heart Valve Dis. 2015;24:528-30.

7. D’Onofrio A, Antonello M, Lachat M, Planer D, Manfrin A, Bagno A, et al. Endovascular treatment of aortic arch aneurysm with a single-branched doublestage stent graft. J Thorac Cardiovasc Surg. 2017; 154:e75-7.

8. Ferrer C, Cao P, Coscarella C, Ferri M, Lovato L, Camparini S, et al. iTalian RegIstry of doUble inner branch stent graft for arch PatHology (the TRIUmPH Registry). J Vasc Surg. 2019;70:672-82.

9. Fillinger MF, Greenberg RK, McKinsey JF, Chaikof EL. Society for Vascular Surgery ad hoc committee on TEVAR reporting standards. Reporting standards for thoracic endovascular aortic repair (TEVAR). J Vasc Surg. 2010;52: 1022-33. 33.e15.

10. Azuma T, Yokoi Y, Yamazaki K. The next generation of fenestrated endografts: results of a clinical trial to support an expanded indication for aortic arch aneurysm treatment. Eur J Cardiothorac Surg. 2013;44: e156-63.
11. Yokoi Y, Azuma T, Yamazaki K. Advantage of a precurved fenestrated endograft for aortic arch disease: simplified arch aneurysm treatment in Japan 2010 and 2011. J Thorac Cardiovasc Surg. 2013;145(suppl):S103-9.

12. Sonesson B, Resch T, Allers M, Malina M. Endovascular total aortic arch replacement by in situ stent graft fenestration technique. J Vasc Surg. 2009;49: 1589-91.

13. Murphy EH, Dimaio JM, Dean W, Jessen ME, Arko FR. Endovascular repair of acute traumatic thoracic aortic transection with laser-assisted in-situ fenestration of a stent-graft covering the left subclavian artery. J Endovasc Ther. 2009;16:457-63.

14. Moulakakis KG, Mylonas SN, Dalainas I, Sfyroeras GS, Markatis F, Kotsis T, et al. The chimney-graft technique for preserving supra-aortic branches: a review. Ann Cardiothorac Surg. 2013;2:339-46.

15. Ricotta JJ II. Endoleak management and postoperative surveillance following endovascular repair of thoracic aortic aneurysms. J Vasc Surg. 2010;52:91S-9S.

16. Bajona P, Quintana E, Schaff HV, Daly RC, Dearani JA, Greason KL, et al. Aortic arch surgery after previous type A dissection repair: results up to 5 years. Interact Cardiovasc Thorac Surg. 2015;21:81-6.

17. Quintana E, Bajona P, Schaff HV, Dearani JA, Daly R, Greason K, et al. Open aortic arch reconstruction after coronary artery bypass surgery: worth the effort? Semin Thorac Cardiovasc Surg. 2016;28:26-35.

18. Gombert A, van Issum L, Barbati ME, Grommes J, Keszei A, Kotelis D, et al. Extra-thoracic supra-aortic bypass surgery is safe in thoracic endovascular aortic repair and arterial occlusive disease treatment. Eur J Vasc Endovasc Surg. 2018; 55:861-6.

Key Words: aortic arch, endovascular therapy 